\title{
SYMPTOMS AND PERSONALITY IN THE DIAGNOSIS OF PHYSICAL ILLNESS
}

\author{
BY \\ J. O. ROBINSON*, Ph.D., AND M. M. WOOD†, B.Sc. \\ From the Department of Psychology*, University College, Cardiff, and \\ The Medical Research Council External Staff $\dagger$, Llandough Hospital, Penarth, Glamorgan
}

The thesis has already been advanced (Robinson, 1964) that a personality characteristic, neuroticism, might play a part in determining whether or not a person with high blood pressure went to hospital. Further work in South Wales now makes it possible to extend this thesis to include another disorder, anaemia.

In the main two decisions have to be made in the process of consultation and diagnosis; the patient has to decide to consult the doctor and the doctor has to decide on the management of the patient's illness. In general the patient will go to the doctor complaining of certain symptoms. The doctor will then decide, on the basis of those symptoms and other observations that he might make, how the patient should be dealt with.

This paper is about such symptoms and their relationship to the objective measurements of haemoglobin level and blood pressure. These measurements often are the basis of diagnoses of anaemia on the one hand or high blood pressure on the other. There is a large overlap between the symptoms ascribed to anaemia, those ascribed to high blood pressure, and certain physical symptoms found in neurotic illness. That is, the symptoms associated with high blood pressure and anaemia in their milder forms are often found in emotional disorder. Most medical practitioners would agree in fact that these three disorders do not have distinct symptom patterns. (It should be emphasized that reference is made here only to the milder forms of anaemia and hypertension. The suggestion will be made later that severe anaemia may have characteristic symptoms. Also, high blood pressure is often progressive and it shortens expectation of life (Pickering, 1961). It, too, in its severe forms, shows signs which are unequivocal.) The purpose of this paper is to suggest that some patients with these conditions share a common personality characteristic which predisposes them to seek medical advice, while there are others in the community with haemoglobin levels just as low, or blood pressure just as high. The latter may have no symptoms or may not see their symptoms as sufficient reason for seeking medical advice, or they may not wish to seek it for other reasons.

Some relevant evidence can be found in the literature. Riseman and Weiss (1930) studied 1,090 hypertensives and showed a large overlap of symptoms reported by them with those reported by 120 patients suffering from so-called "psychoneuritis" (sic). Headache, dizziness, aches and pains, dyspnoea, nervousness, palpitations, and weakness were all both prominent and common to the two groups. The authors concluded that "arterial hypertension is not associated with characteristic symptomatology". They go further and say that "psychic conditions may play a more important role in hypertension than is realized". Although this second claim could be true, no causal link between the two has actually been demonstrated. Ayman and Pratt (1931) also write as though they had shown that emotional difficulties caused hypertension. They studied a group of 100 hypertensives and 50 psychoneurotics. Again there was a substantial overlap of symptoms, headache, pain (sic), dizziness, and fatigue again being prominent.

This early work on high blood pressure was concerned with attempting to demonstrate emotional causes. This and a large part of subsequent 
work on emotional aspects of high blood pressure neglects the existence in the community of apparently symptomless hypertensives. Emotional diffculties are therefore seen as being causally related to high blood pressure. However, it is no less likely that neurotics, who by coincidence have high blood pressure, have coloured the results through a tendency to be caught up in the medical net.

Most general medical texts state that there is a particular symptomatology associated with anaemia, but little evidence exists to support this view. Indeed, one of the few references on this topic (Berry and Nash, 1954) suggests that symptomatology bears no relation at all to anaemia (defining anaemia by the haemoglobin content of the peripheral blood). The symptoms (at least eight are usually included) bear a striking resemblance to those often said to be associated with hypertension or with the psychoneuroses.

\section{Present InVestigations}

Evidence from surveys carried out in South Wales will now be considered. This seems to give further support to the view that personality is important. The correlation between haemoglobin level and symptomatology was investigated in a recent community survey of a small area in the Rhondda Fawr. Subjects answered questionnaires about the symptoms listed in Table I. Questionnaires were of three kinds, the details of which are described elsewhere (Wood and Elwood, 1966). No evidence was found to indicate that any association between haemoglobin level and symptom grade (on a twelve-point scale) existed.

Furthermore, a sample of women with haemoglobin levels below $14 \mathrm{~g}$. and above $10 \mathrm{~g}$. per $100 \mathrm{ml}$. was given oral iron therapy and compared with a matched sample given a placebo (Elwood and Wood, 1966). After 8 weeks of therapy, although the mean haemoglobin level rose by a small but significant amount compared with the placebo group, there was no relationship between change in haemoglobin level and change in symptom grade.

It could be argued that these groups did not contain any individuals with a low enough haemoglobin level to cause any distress. In fact, the survey did include a number of women with haemoglobin levels down to $7.7 \mathrm{~g}$. per $100 \mathrm{ml}$., which most clinicians would accept as very anaemic. These women whose haemoglobin levels were between $7 \cdot 7$ and $10 \mathrm{~g}$. per $100 \mathrm{ml}$. could not be included in the therapy trial mentioned above. Indeed, in these very severe anaemics, the possibility of a relationship between symptoms and haemoglobin level could not be excluded. On one symptom (headache) they showed a significantly higher symptom score than the rest of the population investigated. None of the correlations was significant but most were in the expected direction. The small size of the group (8 patients) makes it difficult to draw firm conclusions (Table II).

TABLE II

CORRELATIONS BETWEEN SIX SYMPTOMS AND HAEMOGLOBIN AND PACKED CELL VOLUME FOR EIGHT FEMALES WITH Hb BELOW $10 \mathrm{~g} .1100 \mathrm{ml}$.

\begin{tabular}{|c|c|c|c|c|}
\hline Examination & & & $\underset{(\mathrm{g} . / 100 \mathrm{ml} .)}{\mathrm{Hb}}$ & $\begin{array}{c}\text { PCV } \\
\text { (Per cent.) }\end{array}$ \\
\hline Symptoms & $\begin{array}{l}\text { Fatigue .. } \\
\text { Dizziness } \\
\text { Palpitations } \\
\text { Irritability } \\
\text { Headache } \\
\text { Breathlessness }\end{array}$ & $\begin{array}{l}\cdots \\
\cdots \\
\cdots \\
\cdots\end{array}$ & $\begin{array}{l}-0.53 \\
-0.21 \\
-0.31 \\
-0.22 \\
-0.60 \\
-0.02\end{array}$ & $\begin{array}{l}-0.34 \\
-0.39 \\
-0.70 \\
-0.41 \\
-0.62 \\
+0.19\end{array}$ \\
\hline
\end{tabular}

The evidence from the blood pressure work in South Wales is a little different. Nothing is known about symptoms, only about neuroticism. Three groups of subjects were studied (Robinson, 1963); a random sample from the complete population of the Rhondda Fach, a group of hospital out-patient neurotics, and a group of hospital out-patients whose diastolic blood pressure exceeded $100 \mathrm{~mm}$. $\mathrm{Hg}$. All these persons were given tests of neuroticism

TABLE I

CORRELATIONS BETWEEN SIX SYMPTOMS AND HAEMOGLOBIN AND PACKED CELL VOLUME, BY SEX

\begin{tabular}{|c|c|c|c|c|c|c|c|c|c|c|c|c|}
\hline No. of Cases & $\cdots$ & $\cdots$ & . & $\cdots$ & . & . & . & . & \multicolumn{2}{|c|}{165} & \multicolumn{2}{|c|}{130} \\
\hline Sex & $\cdots$ & . & . & . & . & $\ldots$ & . & $\ldots$ & \multicolumn{2}{|c|}{ Females } & \multicolumn{2}{|c|}{ Males } \\
\hline Examination & & & & & & & & & $\underset{(\mathrm{g} . / 100 \mathrm{ml} .)}{\mathrm{Hb}}$ & $\begin{array}{c}\text { PCV } \\
\text { (Per cent.) }\end{array}$ & $\underset{(\mathrm{g} . / 100 \mathrm{ml} .)}{\mathrm{Hb}}$ & $\begin{array}{c}\text { PCV } \\
\text { (Per cent.) }\end{array}$ \\
\hline Symptoms & & & $\begin{array}{l}\text { Fatigue } \\
\text { Dizziness } \\
\text { Palpitations } \\
\text { Irritability . } \\
\text { Headache . } \\
\text { Breathlessnes }\end{array}$ & $\begin{array}{l}\cdots \\
\cdots \\
\cdots \\
\text { ess }\end{array}$ & $\begin{array}{l}\cdots \\
\cdots \\
\cdots \\
\cdots\end{array}$ & $\begin{array}{l}\cdots \\
\cdots \\
\cdots \\
\cdots\end{array}$ & $\begin{array}{l}\cdots \\
\cdots \\
\cdots \\
\cdots\end{array}$ & $\begin{array}{l}\cdots \\
\cdots \\
\cdots \\
\cdots\end{array}$ & $\begin{array}{l}-0.00 \\
-0.01 \\
-0.01 \\
-0.02 \\
-0.06 \\
+0.06\end{array}$ & $\begin{array}{l}+0.06 \\
-0.07 \\
+0.00 \\
-0.06 \\
-0.09 \\
+0.13\end{array}$ & $\begin{array}{l}+0.10 \\
-0.06 \\
+0.11 \\
+0.11 \\
-0.09 \\
+0.21\end{array}$ & $\begin{array}{l}+0.10 \\
+0.06 \\
+0.14 \\
+0.02 \\
-0.09 \\
+0.29\end{array}$ \\
\hline
\end{tabular}


and the tests distinguished at a high level of significance between the random sample and the neurotics.

There was no relationship between neuroticism and blood pressure in the random sample, but the hospital hypertensives showed significantly higher scores than the random sample. In view of the lack of any relationship in the random sample, had selection of the hospital group been based on blood pressure alone, one would not have expected such a difference in neuroticism between the two groups. The selection of people with high blood pressure would not have produced a group with high neuroticism scores. Selection must be based then, at least in part, on some other criterion. It has been argued (Robinson, 1964) that this other criterion is neuroticism.

If one could show a connexion between symptoms and neuroticism, then the work on blood pressure would parallel that on anaemia. There is suggestive evidence on this point from another study carried out in South Wales (Rawnsley, 1966) using a shortened version of the Cornell Medical Index, which consisted of many questions about symptoms both primarily "physical" and primarily "psychological". The questionnaire was given to a stratified random sample of the population of the Vale of Glamorgan, and it was found that those who reported many physical symptoms also tended to report many psychological symptoms. The correlation between the two was about $\mathbf{0 . 4}$ for males and about 0.6 for females. Also, individuals diagnosed by a psychiatrist as suffering from psychiatric disorder were found to have more physical, as well as more psychological, symptoms than those not so diagnosed. Culpan, Davies, and Oppenheim (1960) also reported evidence in favour of this. Using the Cornell Medical Index, they showed a significant difference in total score between a healthy group (i.e. not in medical care) and a group of neurotics attending a psychiatric out-patient clinic. The Cornell Medical Index may be criticized for not taking response set into account, but the results mentioned here have been very clear-cut and a relationship between physical symptoms and neuroticism would seem to be not unlikely.

Thus three disorders, mild hypertension, mild anaemia, and neurosis, all have similar symptoms. Symptoms are not related to haemoglobin level and only hypertensives who are also neurotic seem to fall into medical hands. Since both blood pressure and haemoglobin level show considerable natural variation, the most economic explanation of the data at present seems to be that neurotics tend to go to the doctor more readily than others. They tend to be diagnosed according to which bodily system, in the doctor's opinion, is out of line with an accepted norm. If none is apparently out of line, a diagnosis of neurosis may be made, but it is more likely that some treatment will be given for symptoms. This must be a very widespread situation indeed and the occurrence of "free-floating" symptoms must be very common. They may all be traced to some malfunction of the autonomic nervous system brought about by psychic states and in fact a raised blood pressure may be a symptom of such malfunction. But this has not yet been demonstrated.

One of the disorders dealt with here, high blood pressure, is often put under the heading "psychosomatic"; the other, anaemia, is not. Yet the evidence points to the possibility that neuroticism may be an important factor in the declaration of either. In any case, the way in which neuroticism is viewed here as having its effect is not the way that personality factors are generally thought of as operating in psychosomatic illness; they are generally looked upon as "causes" in a much more everyday sense. The evidence cited here leads the writers to wonder whether there might be many other disorders, seen as purely physical disorders, in whose declaration neuroticism is an important factor. If this is the case, then perhaps almost any programme of preventive medicine should employ mass screening techniques, because self-selection by symptoms results in a biased and incomplete group coming into care.

\section{SUMmaRY}

The symptoms generally associated with anaemia are very similar to some physical symptoms which appear in neurotic disorders. A survey is described which suggests that these symptoms are not related to haemoglobin level. These results are in many ways similar to those of a previous survey on blood pressure. There was a low correlation between blood pressure and neuroticism in a random sample from a defined population, yet a clinic group with high blood pressure had high neuroticism scores. It is argued that, although anaemia and hypertension are regarded as physical disorders, in their early stages neuroticism plays a large part in their declaration.

The authors wish to thank Dr J. G. Ingham for his sympathetic supervision of the work reported here and for his constant support and encouragement. They also acknowledge with thanks the co-operation and help of Prof. A. L. Cochrane and Dr P. C. Elwood of the Medical Research Council Epidemiology Research Unit. 


\section{REFERENCES}

Ayman, D., and Pratt, J. H. (1931). Arch. intern. Med., $47,675$.

Berry, W. T. C., and Nash, F. A. (1954). Brit. med. J., $1,918$.

Culpan, R. H., Davies, B. M., and Oppenheim, A. N. (1960). Ibid., 1, 855.

Elwood, P. C., and Wood, M. M. (1966). Brit. J. prev. soc. Med., 20, 172.
Pickering, G. (1961). "The Nature of Essential Hypertension." Churchill, London.

Rawnsley, K. (1966). J. psychosom. Res., 10, 84.

Riseman, J. E. F., and Weiss, S. (1930). Amer. J. med. Sci., 180, 47.

Robinson, J. O. (1963). Brit. J. soc. clin. Psychol., 2, 56. - (1964). J. psychosom. Res., 8, 239.

Wood, M. M., and Elwood, P. C. (1966). Brit. J. prev. soc. Med., 20, 117. 